\title{
Particulate and Microbial Contamination in In-Use Admixed Parenteral Nutrition Solutions
}

\author{
Shigeharu OIE and Akira KAmIY** \\ Department of Pharmacy, Yamaguchi University Hospital; 1-1-1 Minamikogushi, Ube 755-8505, Japan. \\ Received May 19, 2005; accepted September 25, 2005
}

\begin{abstract}
We evaluated particulate and microbial contamination in a total of 192 samples of in-use admixed and unadmixed parenteral nutrition solutions remaining in infusion bags in 10 hospitals. The mean numbers (range) of drug glass ampoules, plastic ampoules, and vials used in a total of 192 admixed solutions were $3.38(1-13), 0.79$ $(0-7)$, and $1.2(0-8)$, respectively. The mean number of particles (range) contained in the 192 samples according to the particle size (diameter) was $960.9(30-9539) / \mathrm{ml}$ for particles $\geq 1.3 \mu \mathrm{m}, 42.8(0-587) / \mathrm{ml}$ for those $\geq$ $5 \mu \mathrm{m}, 6.4(0-146) / \mathrm{ml}$ for those $\geq 10 \mu \mathrm{m}$, and $0.09(0-1) / \mathrm{ml}$ for those $\geq 50 \mu \mathrm{m}$. The number of particles $\geq 1.3 \mu \mathrm{m}$ in diameter was significantly higher in the 192 samples than in 7 samples (controls) of solutions not mixed with any ampoule or vial $(p<0.0001)$. In addition, the number of particles $\geq 1.3 \mu \mathrm{m}$ in diameter was significantly higher in samples of solutions mixed with 4-13 glass ampoules than in those of solutions mixed with $1-3$ glass ampoules $(p<0.01)$. On the other hand, none of the 199 samples showed bacteria or fungi/ $\mathbf{5} \mathrm{ml}$ residual solution. Measures against particulate contamination of admixed parenteral nutrition solutions are necessary.
\end{abstract}

Key words parenteral nutrition; admixture; contamination; glass; rubber; filter

Particulate matters such as glass particles that enter the body, being contained in infusion solutions not only cause infusion-related phlebitis but also have been suggested to damage various organs such as the lungs, brain, kidneys, liver, and spleen. ${ }^{1-4)}$ However, in Asian countries such as Japan, adequate attention is not paid to particulate contamination of parenteral solutions. For example, many drugs in glass ampoules are added to parenteral nutrition solutions, and preuse filtration is rarely performed in the preparation of parenteral nutrition solutions in the dispensary or ward. In addition, many medical institutions do not use in-line filters at the time of administration of admixed parenteral nutrition solutions. One of the reasons for the lack of adequate attention to particulate contamination of parenteral solutions may be poor recognition of this contamination because of only a few previous studies on in-use admixed parenteral nutrition solutions. ${ }^{5-7)}$ Therefore, we evaluated particulate contamination of in-use admixed parenteral nutrition solutions and also microbial contamination of these solutions.

\section{MATERIALS AND METHODS}

We collected residual solutions in bags of in-use parenteral nutrition solutions in 10 hospitals (215-756 beds) in Yamaguchi Prefecture, Japan, and evaluated particulate and microbial contamination in these residual solutions (total, 199 samples). Seven of the 199 samples were used as controls because they had not been mixed with ampoules or vials (unadmixed parenteral nutrition solutions).

The size and number of particles were measured using a light blockage particle counter KL-04 (Rion K.K., Tokyo, Japan). In addition, the volume of the residual solution in the bag was measured. Of the 192 samples, one $(50 \mathrm{ml}$ residual solution) [termed admixed solution A: composition; one bag of $1700 \mathrm{ml}$ sugar/electrolytes/amino acid, one vial of a vitamin complex preparation $\left(\right.$ Maltamin $\left.^{\circledR}\right)$, two glass ampoules of $1 \mathrm{ml} / \mathrm{A}$ panthol $\left(\mathrm{Pantol}^{\mathbb{B}}\right)$, two glass ampoules of $20 \mathrm{ml} / \mathrm{A}$ sodium chloride (Conclyte- $\mathrm{Na}^{\circledR}$ ), two glass ampoules of $2 \mathrm{ml} / \mathrm{A}$ metoclopramide $\left(\right.$ Primperan $^{\circledR}$ ), and two glass am- poules of $10 \mathrm{ml} / \mathrm{A}$ potassium L-aspartate $\left(\right.$ Aspara $\left.\mathrm{K}^{\circledR}\right)$ ] was passed through $0.22 \mu \mathrm{m}$ membrane filters, $5 \mathrm{~cm}$ in diameter (Nippon Becton Dickinson Co., Tokyo, Japan), and the particles on this filter were observed and identified using a scanning electron microscope JSM-5600LV coupled to an energy dispersion spectroscope JEO-2200 (JMS, Tokyo, Japan).

Microorganisms were quantified by the filter filtration method. The residual solution $(5 \mathrm{ml})$ in the bag was passed through $0.22 \mu \mathrm{m}$ membrane filters $(5 \mathrm{~cm}$ in diameter), and $100 \mathrm{ml}$ sterile physiological solution was passed through the filters to eliminate carry-overs such as sugar and amino acid on the filter. The filters were placed on Trypticase soy agar II with 5\% sheep blood (Nippon Becton Dickinson Co., Tokyo, Japan) and incubated for $1-7 \mathrm{~d}$ at $30^{\circ} \mathrm{C}$.

The number of particles in residual solutions was compared according to the particle size $(\geq 1.3 \mu \mathrm{m}, \geq 5 \mu \mathrm{m}$, $\geq 10 \mu \mathrm{m}, \geq 50 \mu \mathrm{m}$ ) between unadmixed parenteral nutrition solution samples $(n=7)$ and admixed parenteral nutrition solution samples $(n=192)$ by the Wilcoxon rank sum test, and $p$-values were obtained. In addition, the admixed parenteral nutrition solution samples $(n=192)$ were classified into those mixed with a total of $1-3$ glass ampoules $(n=129)$ and those mixed with a total of 4-13 glass ampoules $(n=63)$, and the number of particles in residual solutions was compared according to the particle size $(\geq 1.3 \mu \mathrm{m}, \geq 5 \mu \mathrm{m}$, $\geq 10 \mu \mathrm{m}, \geq 50 \mu \mathrm{m})$ by the Wilcoxon rank sum test, and $p$ values were obtained.

\section{RESULTS}

The mean volume (range) of the 199 residual solution samples of in-use parenteral nutrition solutions was 50 (1060) $\mathrm{ml}$. Of the 199 samples, 192 samples were admixed parenteral nutrition solutions. The mean number (range) of glass ampoules, plastic ampoules, and vials that had been mixed with these solutions were $3.38(1-13), 0.79(0-7)$, and 1.2 $(0-8)$, respectively. Table 1 shows the diameter and number of particles in the 192 samples and 7 control samples (unadmixed parenteral nutrition solutions). The number of parti- 
Table 1. Mean (Range) of Particles/ml in In-Use Various Parenteral Nutrition Solution

\begin{tabular}{|c|c|c|c|c|}
\hline \multirow{2}{*}{ Solution } & \multicolumn{4}{|c|}{ Particles greater than } \\
\hline & $1.3 \mu \mathrm{m}$ & $5 \mu \mathrm{m}$ & $10 \mu \mathrm{m}$ & $50 \mu \mathrm{m}$ \\
\hline Unadmixed solutions $(n=7)$ & $\begin{array}{l}62.7 \\
(8-146)\end{array}$ & $\begin{array}{l}1.7 \\
(0-4)\end{array}$ & $\begin{array}{l}0.4 \\
(0-2)\end{array}$ & 0 \\
\hline Admixed solutions $(n=192)$ & $\begin{array}{l}960.9 * \\
(30-9539)\end{array}$ & $\begin{array}{l}42.8^{*} \\
(0-587)\end{array}$ & $\begin{array}{l}6.4 * * \\
(0-146)\end{array}$ & $\begin{array}{l}0.09 \\
(0-1)\end{array}$ \\
\hline Solutions mixed with $1-3$ glass ampoules $(n=129)$ & $\begin{array}{l}862.1 \\
(30-5707)\end{array}$ & $(0-176)$ & $(0-24)$ & $(0-1)$ \\
\hline Solutions mixed with $4-13$ glass ampoules $(n=63)$ & $\begin{array}{l}1163.4 * * * \\
(142-9539)\end{array}$ & $\begin{array}{l}66.2 * * \\
(4-587)\end{array}$ & $\begin{array}{l}10.6^{* * *} \\
(1-146)\end{array}$ & $\begin{array}{l}0.08 \\
(0-1)\end{array}$ \\
\hline
\end{tabular}

$* p<0.0001, * * p<0.001, * * * p<0.01$.

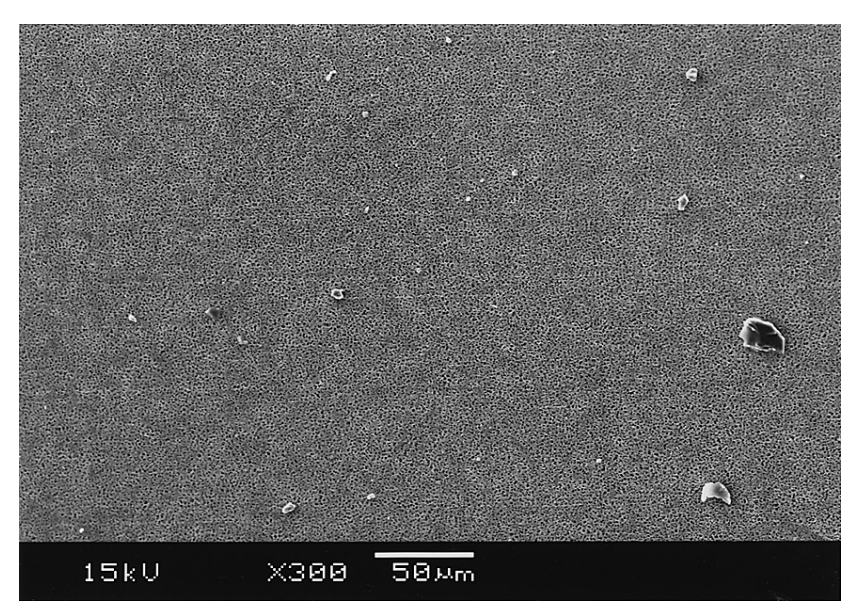

Fig. 1. Scanning Electron Micrograph of $0.22 \mu \mathrm{m}$ Membrane Filters after Filtration of Admixed Solution A

cles $\geq 1.3 \mu \mathrm{m}$ in diameter was significantly higher in the 192 admixed solution samples than in the 7 unadmixed control samples $(p<0.0001)$ and also in samples of solutions mixed with 4-13 glass ampoules than those of solutions mixed with $1-3$ glass ampoules $(p<0.01)$.

Figure 1 shows a scanning electron micrograph of particles on the filter after filtration of $50 \mathrm{ml}$ residual solution of admixed solution $\mathrm{A}$, which was a standard sample in terms of the number of particles $\geq 1.3 \mu \mathrm{m}(1034 / \mathrm{ml})$ among the 192 samples. In this figure, 20 particles can be counted. The area of this screen was about $0.4 \mathrm{~mm} \times 0.25 \mathrm{~mm}=0.1 \mathrm{~mm}^{2}$, and the area of the filter was $1962 \mathrm{~mm}^{2}$. Therefore, even if uneven distribution of particles on the filter was taken into consideration, there may be more than tens of thousands of particles on the filter. Figure 2 shows a scanning electron micrograph of two types of particles on the filter after filtration of admixed solution A and results of the identification of these particles by energy dispersion spectroscopy. Figure 2a suggested glass particles, and Fig. $2 \mathrm{~b}$ suggested rubber particles.

\section{DISCUSSION}

Though the rates of microbial contamination in in-use admixed parenteral nutrition solutions has been reported to be $0-8.2 \%,{ }^{8-13)}$ it was $0 \%$ in this study. Our results support the validity of the description in the guidelines by Centers for Disease Control and Prevention (CDC), "Do not use in-line filters routinely for infection control purpose". ${ }^{14)}$ However, in Japan where glass ampoules are frequently used when parenteral nutrition solutions are admixed, unlike western countries that rarely use them, the number of particles contained in-use admixed parenteral nutrition solutions was considerably high. The mean number of particles $\geq 1.3 \mu \mathrm{m}$ in the 192 residual solution samples examined in this study was 960.9/ $\mathrm{ml}$. Since the mean residual solution volume was $50 \mathrm{ml}$, there were $48000(960 \times 50)$ particles $\geq 1.3 \mu \mathrm{m}$ in diameter per bag. Therefore, in terms of particulate contamination, the description in the CDC guidelines, "Do not use in-line filters routinely..." may not be appropriate in Japan.

A measure against particulate contamination of admixed parenteral nutrition solutions may be pre-use filtration in the pharmacy. However, in Asian countries such as Japan, the preparation of parenteral nutrition solutions in pharmacy is not common. Therefore, pre-use filtration in the pharmacy is not realistic.

Another measure for particulate contamination of admixed parenteral nutrition solutions may be a reduction in the use of glass ampoules by using plastic ampoules that less frequently cause particulate matters at the time of ampoule cutting. ${ }^{15)}$ However, there are only a few parenteral solutions in the form of plastic ampoules such as 5\% glucose, physiological saline, and distilled water for injection. The number of drugs in glass ampoules is overwhelmingly higher than that of drugs in plastic ampoules, and the use of glass ampoules is unavoidable at present. As shown by our results, even when the number of glass ampoules was $1-3$, a considerable number of particles were present in admixed parenteral nutrition solutions. Therefore, a reduction in the number of glass ampoules can not be an adequate measure.

Therefore, to prevent entrance of particulates into the body, the use of in-line filters is recommended. ${ }^{16,17)}$ In Japan, in-line filters are used at the time of administration of admixed parenteral nutrition solution in some medical institutions but not in others. The reason is the high cost. However, considering the high number of particles contained in admixed parenteral nutrition solutions, in-line filters should be used at the time of administration of admixed parenteral nutrition solutions. 
(a)
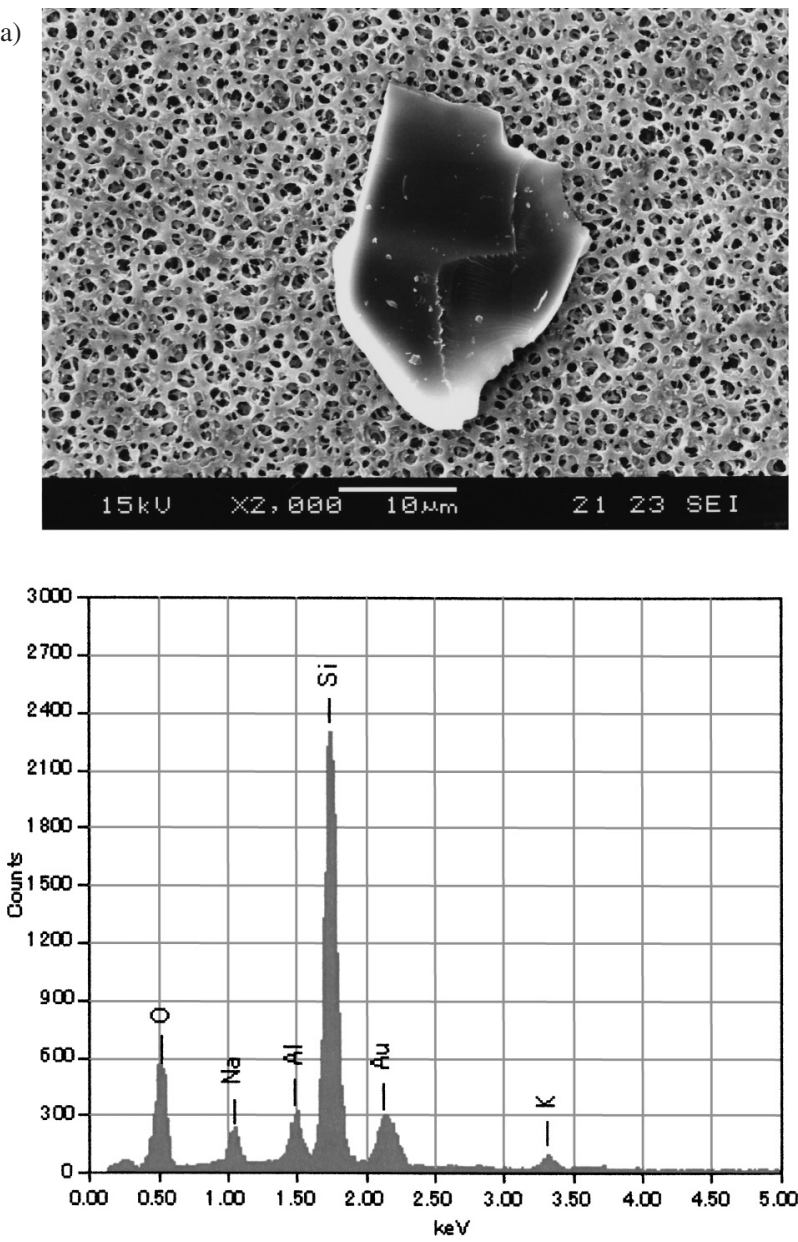

(b)
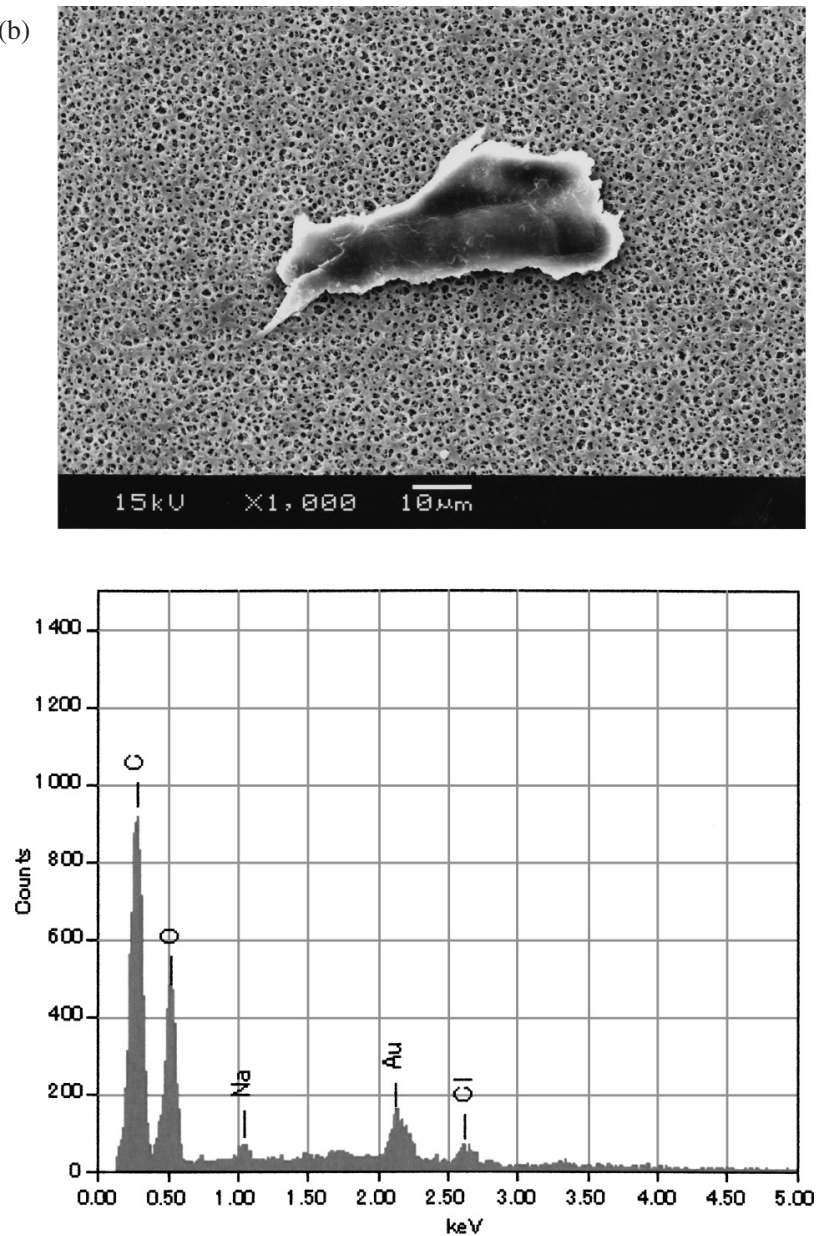

Fig. 2. Identification of Two Types of Particles by Scanning Electron Microscopy Coupled to Energy Dispersion Spectroscopy

(a) suggests glass particles, and (b) suggests rubber particles.

\section{REFERENCES}

1) DeLuca P. P., Rapp R. P., Bivins B., McKean H. E., Griffen W. O., Am. J. Hosp. Pharm., 32, 1001-1007 (1975).

2) Schroeder H. G., DeLuca P. P., Am. J. Hosp. Pharm., 33, 543-546 (1976).

3) Falchuk K. H., Peterson L., McNeil B. J., N. Engl. J. Med., 312, 7882 (1985).

4) Turco S. J., Davis N. M., J. Am. Med. Assoc., 217, 81-82 (1971).

5) Foloni L. U., Rochat M. H., Trouiller P., Calop J. Y., J. Parenter. Sci. Technol., 47, 311-315 (1993).

6) Ahnefeld F. W., Klaus E., Anaesthesist, 26, 476- 484 (1977).

7) Sabon R. L., Cheng E. Y., Stommel K. A., Hennen C. R., Anesthesiology, 70, 859-862 (1989).

8) Bronson M. H., Stennett D. J., Egging P. K., J. Parenter. Enteral. Nutr., 12, 25-28 (1988)

9) Weil D. C., Arnow P. M., J. Clin. Microbiol., 26, 1787-1790 (1988).
10) Spiliotis J., Arvaniti A., Tsirigotis M., Angelopoulou H., Kalfarentzos F., Instrument. Techniq. Clin. Med., 30, 302-303 (1989).

11) Macías A. E., Munoz J. M., Bruckner D. A., Rodríguez A. B., Guerrero F. J., Medina H., Gallaga J. C., Cortés G., Am. J. Infect. Control, 27, 285-290 (1999).

12) Scott E. M., Gorman S. P., Wyatt T. D., Magill E. A., J. Clin. Hosp. Pharm., 10, 79-88 (1985).

13) Hansen E. W., Nielsen P. L., J. Clin. Pharm. Ther., 12, 325-331 (1987).

14) Centers for Disease Control and Prevention, Am. J. Infect. Control, 24 , 262-293 (1996).

15) Oppenheim R. C., Gillies I. R., J. Pharm. Pharmacol., 38, 344-347 (1986).

16) Lye S. T., Hwang N. C., Anaesthesia, 58, 84-105 (2003).

17) Walpot H., Franke R. P., Burchard W. G., Agternkamp C., Müller F. G., Mittenmayer C., Kalff G., Anaethesist, 38, 544-548 (1989). 